\title{
Kinetics of water vapor adsorption by vacuum-dried jujube powder
}

\author{
Jun Ho Lee*, Li Zuo \\ Department of Food Engineering, Daegu University, Gyeongbuk 38453, Korea
}

\begin{abstract}
Water vapor adsorption kinetics of vacuum-dried jujube powder were investigated in temperature and relative humidity ranges of 10 to $40{ }^{\circ} \mathrm{C}$ and 32 to $75 \%$, respectively. Water vapor was initially adsorbed rapidly and then reached equilibrium condition slowly. Reaction rate constant for water vapor adsorption of vacuum-dried jujube powder increased with an increase in temperature. The temperature dependency of water activity followed the Clausius-Clapeyron equation. The net isosteric heat of sorption increased with an increase in water activity. Good straight lines were obtained with plotting of $1 /\left(m-m_{0}\right)$ vs. $1 / t$. It was found that water vapor adsorption kinetics of vacuum-dried jujube powder was accurately described by a simple empirical model, and temperature dependency of the reaction rate constant followed the Arrhenius-type equation. The activation energy ranged from 50.90 to $56.00 \mathrm{~kJ} / \mathrm{mol}$ depending on relative humidity. Arrhenius kinetic parameters $\left(E_{a}\right.$ and $\left.\boldsymbol{k}_{0}\right)$ for water vapor adsorption by vacuum-dried jujube powder showed an effect between the parameters with the isokinetic temperature of 302.51 $K$. The information on water vapor adsorption kinetics of vacuum-dried jujube powder can be used to establish the optimum condition for storage and processing of jujube.
\end{abstract}

Key words : vacuum drying, jujube powder, water vapor adsorption, kinetics, compensation effect

\section{Introduction}

Zizyphus jujuba Miller belonging to the family Rhamnaceae, is found in many countries especially in the subtropical and tropical regions of Australia, southern and eastern Asia, and Europe (1). Jujube fruit is commonly used as a crude drug in traditional Oriental medicine for many years, and is known to effectively prevent some diseases, such as tumors and cardiovascular diseases (2). Fresh fruit contains abundant amounts of nutrients, especially vitamin C: 10-fold as much as that in other fruits. It is increasingly consumed as fresh or used as food additives and flavoring agents (3). The fruits also have been reported in several food processing products such as compotes, alcoholic beverages, cakes, and bread (4)

The water vapor barrier properties of fruit-based powders,

*Corresponding author. E-mail : leejun@daegu.ac.kr

Phone : 82-53-850-6531, Fax : 82-53-850-6539

Received 29 May 2017; Revised 9 July 2017; Accepted 10 July 2017.

Copyright (c) The Korean Society of Food Preservation. All rights reserved. like vacuum-dried jujube powder, are significantly influenced by the presence of moisture. Therefore, an understanding and evaluation of water adsorption behavior of the jujube powder are essential for their application in the development of various types of stable functional food additives or ingredients. To understand the whole adsorption process, the studies may be done by measuring either the equilibrium condition or the rate of approach to equilibrium. The former can be done through determining the water adsorption isotherms; however, isotherms only explain the final equilibrium condition. The latter is done by plotting adsorption curves (weight vs. time at constant relative humidity and temperature). To the best of our knowledge, no information is available on the water vapor adsorption kinetics of jujube powder in any forms.

The objective of the present study was to provide reliable experimental data regarding initial water vapor adsorption behavior of vacuum-dried jujube powder and to identify and test simple relationships to characterize the initial water vapor adsorption kinetics at different temperatures and water activity levels. 


\section{Materials and Methods}

\section{Materials}

Fresh jujube (Ziziphus jujuba Mill.), harvested in Gyeongsan, Gyeongbuk, Korea at October in 2010, was purchased from a local market and stored at room temperature before use. Mean moisture content of the sample was $75.29 \%$ (wet basis), measured in triplicate by using a hot-air oven (DMC-122SP, Daeil Engineering Co., Seoul, Korea) at $105^{\circ} \mathrm{C}$ for $24 \mathrm{~h}$.

\section{Experimental procedure}

After sliced to 3-4 $\mathrm{mm}$ in thickness, fresh jujube slices were spread in a single layer on a tray and dried by a vacuum dry oven (VOS-301SD, Tokyo Rikakikai Co., Ltd., Tokyo, Japan) at $60^{\circ} \mathrm{C}$ and milled into particle size of $250 \mu \mathrm{m}$ by a 60-mesh sieve (D-55743, Fritsch GmbH, Idar-Oberstein, Germany). Approximately $1.0 \mathrm{~g}$ of jujube powder was placed on an aluminum dish and stored at the selected relative humidities ranging from $31-77 \%$ and temperatures ranging from $10-40^{\circ} \mathrm{C}$. The relative humidities $(\mathrm{RH})$ were prepared by using saturated-salt aqueous solutions of $\mathrm{MgCl}_{2}, \mathrm{NaBr}$, and $\mathrm{NaCl}$, respectively. The increase in weight of the jujube powder was recorded in duplicate every $30 \mathrm{~min}$ during the water vapor adsorption process. The water vapor adsorption rates of jujube powder were determined from the weight gain of jujube.

\section{Water activity measurement}

Water activity inside each desiccator after attaining equilibrium with each saturated salt solution at each temperature was determined using a Thermo Recorder (TR-72U, T\&D Corp., Nagano-ken, Japan). Temperature dependency of water activity was tested using the ClausiusClapeyron equation as follows:

$$
\begin{gathered}
d \ln a \\
(1 / \quad)
\end{gathered}=-\begin{gathered}
\Delta H \\
R
\end{gathered}
$$

where $a_{W}$ is the water activity, $T$ is the absolute temperature $(\mathrm{K}), \Delta H$ is net isosteric heat of sorption $(\mathrm{kJ} / \mathrm{mol})$, and $\mathrm{R}$ is the universal gas constant $(8.314 \mathrm{~J} / \mathrm{mol} \cdot \mathrm{K})$.

\section{Data analysis}

Water vapor adsorption curves of the jujube powder were obtained by plotting increase in weight (g) due to water vapor sorption expressed in $\mathrm{g} \mathrm{H}_{2} \mathrm{O} / \mathrm{g}$ dry solid against adsorption time (h). The rate of constant of water sorption process was determined by a linear form as follows:

$$
\stackrel{1}{m-m_{0}}=\frac{1}{k\left(m_{e}-m_{o}\right) t}+\frac{1}{m_{e}-m_{o}}
$$

where $m_{e}$ and $m_{0}$ are the saturation moisture constant and the initial moisture content, respectively, and $k$ is the rate constant of the sorption process. The inverse of $m-m_{o}$ vs. inverse of $t$ to get a straight line. The reaction rate constant was determined by taking inverse of the slope value.

The temperature dependency of $k$ value was determined by an Arrhenius-type equation as below:

$$
k=k_{0} \exp \left(-E_{a} / R T\right)
$$

where $k_{o}$ is a pre-exponential factor, $E_{a}$ is the activation energy for hydration process, $R$ is the universal gas constant $(8.314 \mathrm{~J} / \mathrm{mol} \cdot \mathrm{K})$, and $T$ is the absolute temperature $(\mathrm{K})$.

\section{Results and Discussion}

\section{Water activity of saturated salt solutions}

Water activity values and net isosteric heat of sorptions for the saturated salt solutions are summarized in Table 1. The water activity values of saturated salt solutions generally decreased with an increase in temperature. The temperature dependency of water activity followed the Clausius-Clapeyron equation. The net isosteric heat of sorption increased with an increase in water activity. The values for saturated salt solutions of $\mathrm{MgCl}_{2}, \mathrm{NaBr}$, and $\mathrm{NaCl}$ were $3.65,4.82$, and $5.59 \mathrm{~kJ} / \mathrm{mol}$, respectively.

\begin{tabular}{|c|c|c|c|c|c|}
\hline \multirow{2}{*}{ Salt } & \multicolumn{4}{|c|}{ Water activity } & \multirow{2}{*}{$\underset{(\mathrm{kJ} / \mathrm{mol}}{\Delta H^{\mathrm{H}^{2}}}$} \\
\hline & $10^{\circ} \mathrm{C}$ & $20^{\circ} \mathrm{C}$ & $30^{\circ} \mathrm{C}$ & $40^{\circ} \mathrm{C}$ & \\
\hline $\mathrm{MgCl}_{2}$ & 0.35 & 0.34 & 0.31 & 0.31 & 3.65 \\
\hline $\mathrm{NaBr}$ & 0.61 & 0.60 & 0.56 & 0.56 & 4.82 \\
\hline $\mathrm{NaCl}$ & 0.77 & 0.75 & 0.73 & 0.73 & 5.59 \\
\hline
\end{tabular}

Table 1. Water activity values of saturated salt solutions at different temperatures

${ }^{1)}$ Net isosteric heat of sorption.

\section{Water vapor adsorption curves}

Water vapor adsorption behaviors of vacuum-dried jujube powder at different relative humidities and temperatures are 

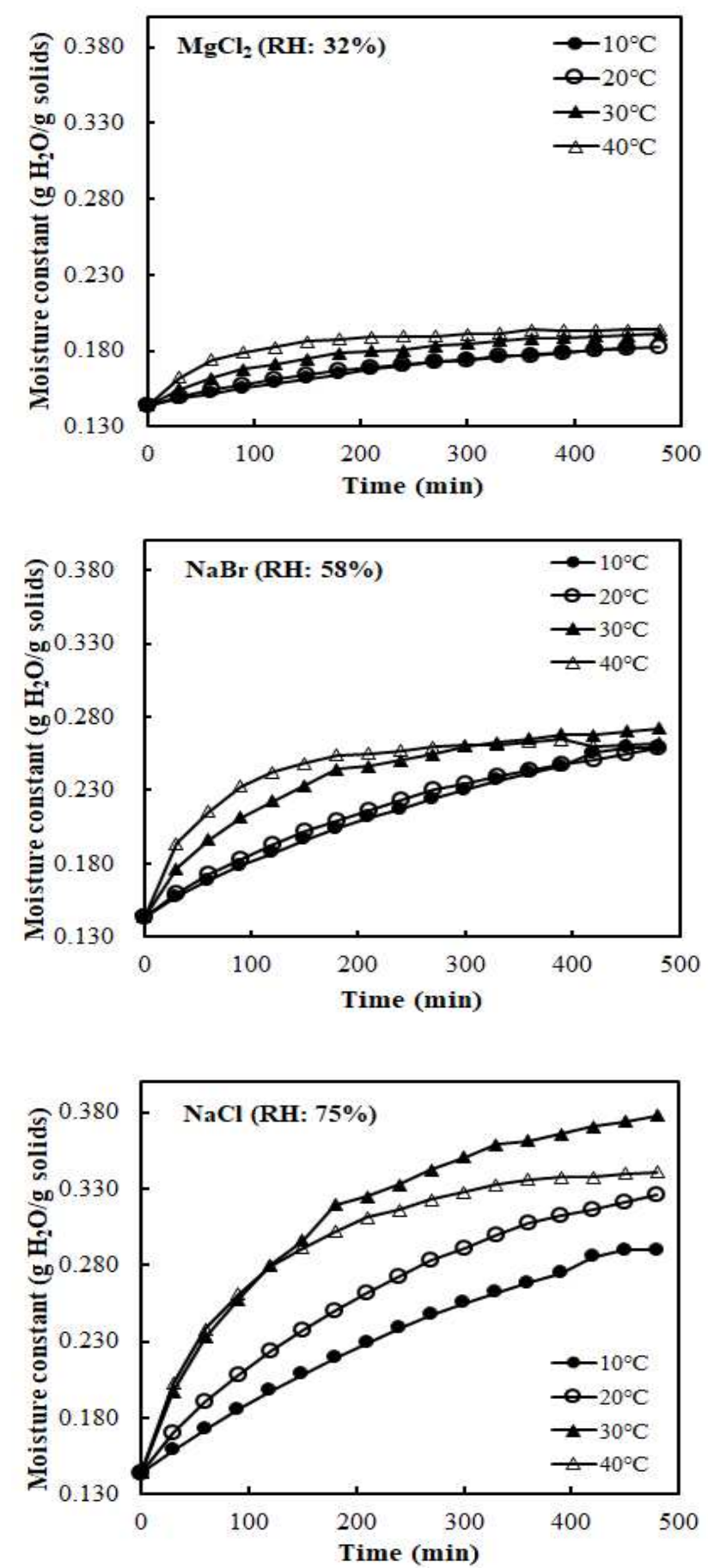

Fig. 1. Water vapor adsorption behaviors of vacuum-dried jujube powder at different temperature and $\mathrm{RH}$ conditions.

shown in Fig. 1. The jujube powder took longer time to reach the plateau and stable moisture contents at higher RH, and it obtained the highest equilibrium moisture contents stored at $40^{\circ} \mathrm{C}$ and $75 \% \mathrm{RH}$. The sorption curves also indicated that the amount of water vapor adsorbed increased with temperature in general. Higher the temperature, sharper the slope. Even though there were some overlaps of the moisture contents for jujube powder stored at higher temperatures (30 and $40^{\circ} \mathrm{C}$ ) with $75 \% \mathrm{RH}$ and lower temperatures (10 and $20^{\circ} \mathrm{C}$ ) with 32 or $58 \% \mathrm{RH}$, the slope of the water vapor adsorption curves generally increased with temperature. Under each RH condition, the rapid initial moisture sorption followed by a slower adsorption at later stages due to the filling capillaries of the surface of jujube powder $(5,6)$. During the process of moisture sorption preceded, the adsorption rate decreased probably due to the filling of free capillary with water vapor (7). The sorption curves also indicated that the amount of water vapor adsorbed increased with the increases in temperature and water activity in general. Similar findings were reported for soybeans (5) and Inonotus obliquus powders (6).

\section{Water vapor adsorption rate}

The inverse of $m-m_{0}$ was plotted against inverse of $t$ following the Eq. B to get a straight line. The reaction rate constant was determined by taking inverse of the slope value. From water vapor adsorption curves, it was found that water vapor adsorption rate varied depending on temperature. Figure 2 shows kinetic plot lines for water vapor adsorption of vacuum-dried jujube powder at different temperatures and RHs. Good linear relationships were observed with high $\mathrm{R}^{2}$-values, indicating that the Arrhenius model is appropriate to describe the temperature dependency of the water vapor adsorption rate of vacuum-dried jujube powders. Regardless of RH conditions, slope of fitted lines was higher at lower temperatures. From the slope value of the lines, water vapor

Table 2. Reaction rate constants for water vapor adsorption of vacuum-dried jujube powder

\begin{tabular}{cccc}
\hline $\begin{array}{c}\text { Saturated salt } \\
\text { solutions }\end{array}$ & Temp. $\left({ }^{\circ} \mathrm{C}\right)$ & $k\left(\times 10^{-3} \mathrm{~g} \mathrm{H}_{2} \mathrm{O} / \mathrm{g}\right.$ dry solid/min $)$ & $\mathrm{R}^{2}$ \\
\hline \multirow{3}{*}{$\mathrm{MgCl}_{2}$} & 10 & 2.11 & 0.998 \\
& 20 & 4.43 & 0.996 \\
& 30 & 7.91 & 0.977 \\
& 40 & 17.40 & 0.988 \\
\hline \multirow{2}{*}{$\mathrm{NaBr}$} & 10 & 2.20 & 0.999 \\
& 20 & 3.17 & 0.998 \\
& 30 & 8.75 & 0.997 \\
& 40 & 20.05 & 0.987 \\
\hline \multirow{3}{*}{$\mathrm{NaCl}$} & 10 & 1.29 & 0.999 \\
& 20 & 3.52 & 0.997 \\
& 30 & 7.41 & 0.997 \\
& 40 & 11.25 & 0.997 \\
\hline
\end{tabular}


adsorption rate constants $(K)$ were calculated and results are summarized in Table 2 . The $k$ values increased as the temperature increased from 10 to $40^{\circ} \mathrm{C}$ at each relative humidity condition. The water vapor adsorption rate for all samples increased with temperature, which is in good agreement with the finding of other researchers $(5,6)$. The range of $\mathrm{R}^{2}$-values was from 0.977 to 0.999 , indicating a
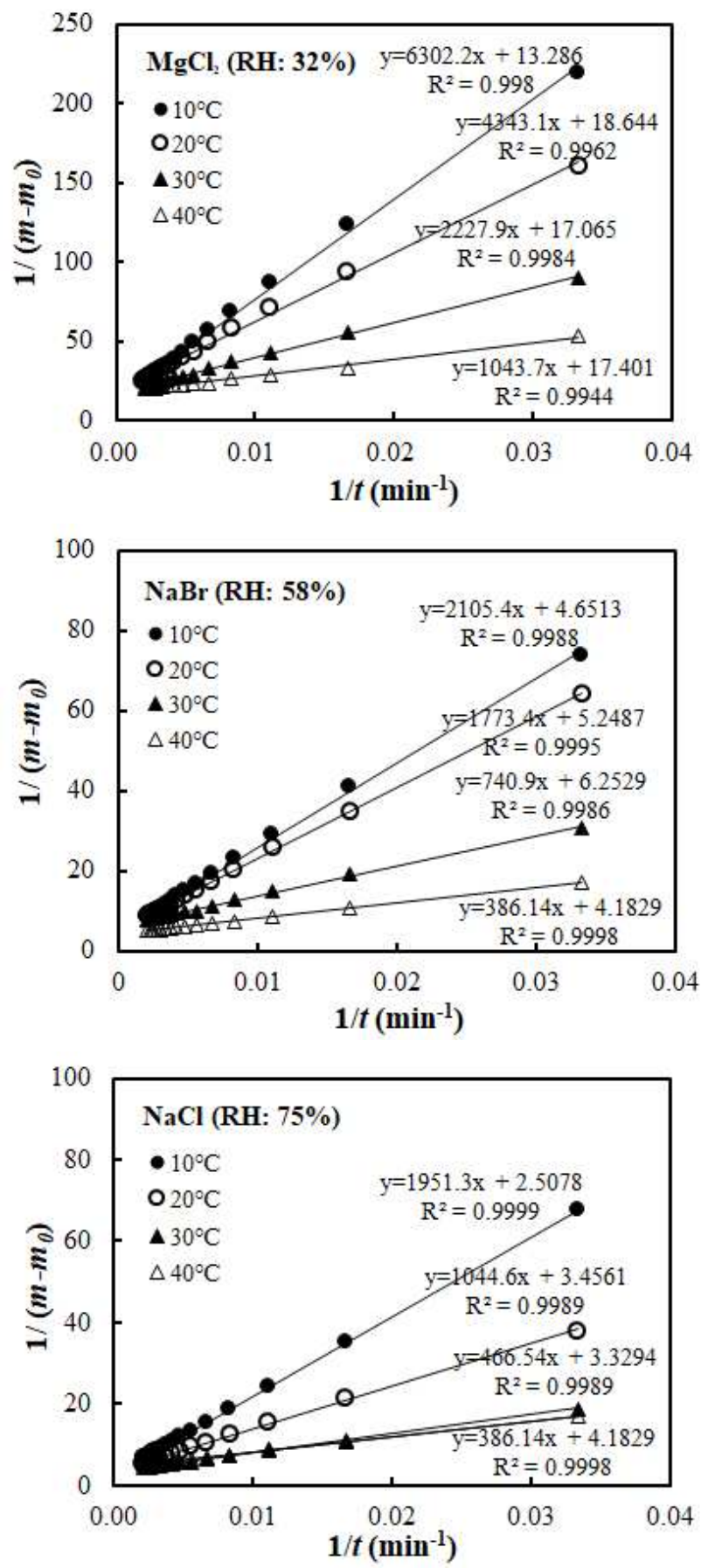

Fig. 2. Adsorption kinetics of vacuum-dried jujube powder determined at different temperature and $\mathrm{RH}$ conditions. good linear relationship. Finally, the temperature dependency of $k$ values could be described using the Arrhenius model.

\section{Effect of temperature}

By using the Arrhenius-type equation in Eq. C, temperature dependency of the water vapor adsorption rate of vacuumdried jujube powder was determined. The temperature dependency of water vapor adsorption rate is shown in Fig. 3. The good linear relationship with high $\mathrm{R}^{2}$-values of 0.995 , 0.961 , and 0.978 , respectively for 32,58 , and $75 \% \mathrm{RH}$ conditions was obtained. This result indicated that Arrhenius model is appropriate to describe the temperature dependency of the water adsorption rate of jujube powder. The Arrhenius kinetic parameters, activation energy $\left(E_{a}\right)$, and pre-exponential factor $\left(k_{0}\right)$ for the water vapor adsorption by the jujube power were determined by linear regression method and results were summarized in Table 3. The activation energy ranged from 50.90 to $56.00 \mathrm{~kJ} / \mathrm{mol}$ depending on the $\mathrm{RH}$. The values are within the range of those reported for the hydration of food stuffs $(5,8,9)$. The activation energy in the middle range of water activity $(\mathrm{NaBr})$ was higher than that of lower and higher ranges of water activity. This indicates that the rate of water vapor sorption by the vacuum-dried jujube powder is more temperature sensitive at the middle range of water activity. Similar observation was made in Inonotus obliquus mushroom powders (6).

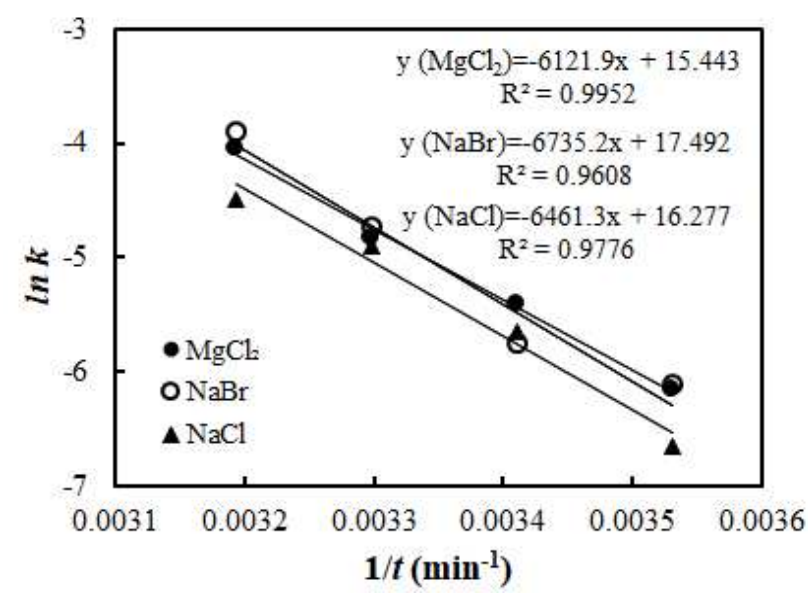

Fig. 3. Temperature dependency of water vapor adsorption kinetics of vacuum-dried jujube powder at different water activities.

\section{Kinetic compensation effect}

Numerical values of kinetic parameters are influenced by the reaction conditions such as reactant concentration, $\mathrm{pH}$, water activity, and so on; however, the Arrhenius kinetic parameters $\left(E_{a}\right.$ and $\left.k_{0}\right)$ for water vapor adsorption rate usually 
Table 3. Kinetic parameters for water vapor adsorption of vacuum-dried jujube powder

\begin{tabular}{cccc}
\hline $\begin{array}{c}\text { Saturated salt } \\
\text { solutions }\end{array}$ & $k_{o}\left(\mathrm{~g} \mathrm{H}_{2} \mathrm{O} / \mathrm{g}\right.$ dry solid/min $)$ & $E_{a}(\mathrm{~kJ} / \mathrm{mol})$ & $\mathrm{R}^{2}$ \\
\hline $\mathrm{MgCl}_{2}$ & $5.093 \times 10^{6}$ & 50.90 & 0.995 \\
$\mathrm{NaBr}$ & $3.951 \times 10^{7}$ & 56.00 & 0.961 \\
$\mathrm{NaCl}$ & $1.173 \times 10^{7}$ & 53.72 & 0.978 \\
\hline
\end{tabular}

show linear relationship between $\ln k_{0}$ and $E_{a}$, which is known as kinetic compensation effect $(6,10)$. The relationship between $E_{a}$ and $k_{0}$ for water vapor adsorption rate of vacuum-dried jujube powder is shown in Fig. 4. This result shows a highly linear relationship between the kinetic parameters, which indicates a systematic variation of one parameter depending on others. This is known as a kinetic compensation effect (11), which is usually observed in a family of reactions with same reaction mechanism. This suggests that $E_{a}$ and $k_{0}$ are not independent of one another and any change in the $E_{a}$ is compensated by changes in $k_{0}$.

This unique relationship can be used for the prediction of reaction rates or other kinetic parameters (12). This linear relationship implies the existence of a unique temperature called isokinetic temperature $\left(T_{c}\right)(11)$, where the rate constants of all reactions in the series have the same value (7), mathematically reflecting the dependence of activation energy on the temperature $(13,14)$. The isokinetic temperature is usually calculated based on the slope from the linear relationship shown in Fig. 4, using the relationship of slope $=1(\mathrm{R} \cdot \mathrm{Tc})$. From the slope, the isokinetic temperature of water vapor adsorption for vacuum-dried jujube powder was determined and found to be $302.51 \mathrm{~K}$, which is in good agreement with for some selected proteins and starch foods (15) with a high degree of linear correlation.

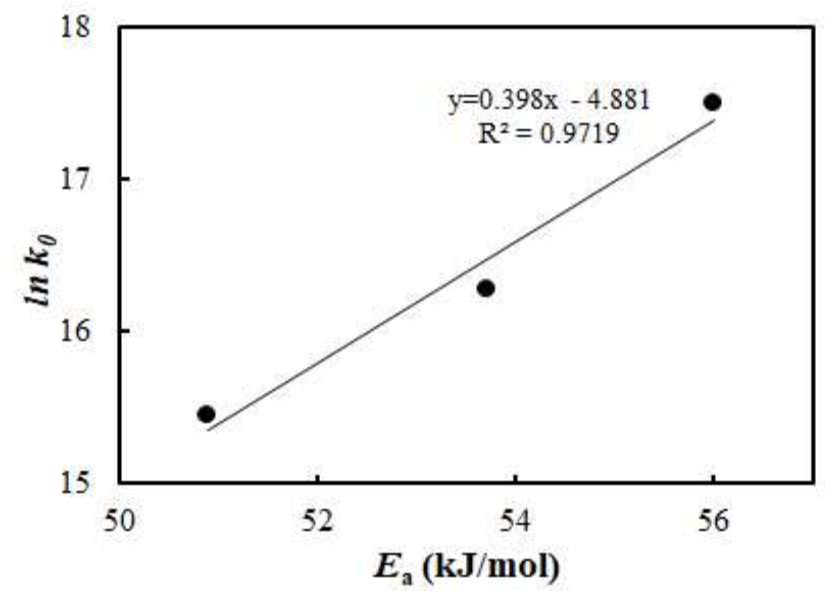

Fig. 4. Kinetic compensation effect of water vapor adsorption of vacuum-dried jujube powder.

\section{References}

1. Gao QH, Wu CS, Wang M (2013) The jujube (Ziziphus jujuba Mill.) fruit: A review of current knowledge of fruit composition and health benefits. J Agric Food Chem, 61, 3351-3363

2. Zhang H, Jiang L, Ye S, Ye Y, Ren F (2010) Systematic evaluation of antioxidant capacities of the ethanolic extract of different tissues of jujube (Ziziphus jujuba Mill.) from China. Food Chem Toxicol, 48, 1461-1465

3. Li JW, Fan LP, Ding SO, Ding XL (2007) Nutritional composition of five cultivars of Chinese jujube. Food Chem, 103, 454-460

4. Shobha D, Bharati P (2007) Value addition to Ber (Zyziphus mauritiana Lamk.) through preparation of pickle. Karnataka J Agric Sci, 20, 353-355

5. Rhim JW (2003) Hydration kinetics of soybeans. Food Sci Biotechnol, 12, 303-306

6. Lee MJ, Seog EJ, Lee JH (2007) Kinetics of initial water vapor adsorption by Inonotus obliquus mushroom powders. J Food Sci Nutr, 12, 111-114

7. Seog EJ, Zuo L, Lee JH, Rhim JW (2008) Kinetics of water vapor adsorption by chitosan-based nanocomposite films. Food Sci Biotechnol, 17, 330-335

8. Hsu KH, Kim CJ, Wilson LA (1983) Factors affecting water uptake of soybeans during soaking. Cereal Chem, 60, 208-211

9. Sopade PA, Obekpa JA (1990) Modelling water absorption in soybean, cowpea and peanuts at three temperatures using Peleg's equation. J Food Sci, 55, 1084-1087

10. Rhim JW (2002) Kinetic compensation relations for texture changes in sweet potatoes during heating. Food Sci Biotechnol, 11, 29-33

11. Rhim JW, Nunes RV, Jones VA, Swartzel KR (1989) Appearance of a kinetic compensation effect in the acid-catalyzed hydrolysis of disaccharides. J Food Sci, 54, 222-223

12. Aguerre RJ, Suarez C, Viollaz PE (1986) Enthalpyentropy compensation in sorption phenomena: Application to the prediction of the effect of temperature on food isotherms. J Food Sci, 51, 1547-1549

13. Exner O (1970) Determination of isokinetic temperature. Nature, 227, 366-367

14. Peled A, Schein LB (1991) The thermal activation compensation effect and the isokinetic temperature relation to physical models. Physica Scripta, 44, 304-309

15. Fontan CF, Chirife J, Sancho E, Iglesias HA (1982) Analysis of a model for water sorption phenomena in foods. J Food Sci, 47, 1590-1594 